\title{
Tempos, espaços e organização do trabalho escolar em três expressões de governos autoritários brasileiros: 1931, 1961 e 1971 - estudo histórico-jurídico comparado do Ensino Secundário
}

\section{Time, space and organization of the school work in three expressions of the Brazilian authoritarian regime (1931, 1961 and 1971): a comparative historical-juridical study of the Secondary School}

\author{
Eurize Caldas Pessanha ${ }^{1}$ \\ Fabiany de Cássia Tavares Silva ${ }^{1}$
}

\begin{abstract}
RESUMO
O Brasil viveu longo período de autoritarismo, iniciado com o governo provisório de Getúlio Vargas, transformado no Estado Novo em 1937, interrompido por uma "ilha" de democratização (1945-1964), que atingiu o auge com a ditadura civil-militar (1964-1985). Três marcos na legislação para o ensino secundário possibilitam a problematização das relações entre educação e ditaduras: "Reforma Francisco Campos" (1931); a Lei 4.024 de 1961 (LDB), e a Lei 5.692 de 1971. Cada uma delas explicitou e induziu diretrizes curriculares que alteraram a organização do espaço, do tempo e do trabalho escolar nas escolas. Este texto ancora-se no estudo e na análise de um dos períodos da história da educação brasileira conhecido como História da escola pública propriamente dita, particularmente, nas etapas de regulamentação nacional do ensino e do ideário pedagógico renovador (1931-1961), e no início da unificação normativa da educação nacional e da concepção produtivista de escola (1961). Para tanto, parte-se da hipó-
\end{abstract}

1 Universidade Federal de Mato Grosso do Sul. Campo Grande, Mato Grosso do Sul, Brasil. Avenida Senador Filinto Müller, nº 2443 - Cidade Universitária. CEP: 79070-900. 
tese de que, no Brasil, o equilíbrio entre essas etapas estava associado à necessidade de alargamento da base social de apoio, de consolidação dos alicerces, de fundação da mentalidade das novas gerações nos princípios da educação cívica, possível apenas por meio de um programa educativo racionalmente concebido e sistematicamente implementado e sustentado, o ensino secundário. Dito de outra forma, a questão da moralidade em associação estreita com o civismo, a solidariedade social, a disciplina e a ordem, a justiça, o patriotismo. Conclui-se que o tempo, o espaço e a organização do trabalho escolar, no conjunto das medidas adotadas na organização do ensino secundário, asseguravam a instituição e a comunicação de diferentes signos e significados no mercado simbólico e alimentavam uma sistemática de inspeção para alcançar os níveis mais altos de racionalidade, controle e eficácia característicos dos períodos de autoritarismo.

Palavras-chave: ensino secundário; ditadura; espaço; tempo; organização do trabalho escolar.

\begin{abstract}
Brazil lived for a long period under the authoritarian regime which started with Getulio Vargas provisional government, that in 1937 became the Estado Novo (New State), but it was interrupted by an "island" of democratization (1945-1964), and reached its peak during the civil-military dictatorship (1964-1985). Three marks in the legislation for secondary education enabled questioning the relations between education and dictatorship: the "Francisco Campos Reform" (1931); The Law 4.024 (LDB), in 1961, and the Law 5.692 , in 1971. Each of them stated and induced curriculum guidelines that changed the time, space and the organization of the school work. This text is anchored in the study and analysis of the periods of the Brazilian education history known as the Public School Itself History, particularly in the phases of the national regulation process of teaching and the pedagogical renovator ideology. (1931-1961), and in the beginning of the normative unification of national education and the productivist conception of school (1961). To do so, we start from the hypothesis that in Brazil, the balance between these phases was associated with the need for broadening the social base of political support, for the consolidation of the pillars, the foundation of the mentality of younger generations on the principles of civic education, only possible through an educational program designed, implemented and sustained rationally and systematically: the middle school. In other words, we are dealing with the question of morality in close association with citizenship, social solidarity, discipline and order, justice, and patriotism. We conclude that the time, space and organization of school work, in the set of measures taken in the organization of secondary education ensured the institution and communication of different signs and symbolic meanings in
\end{abstract}


the symbolic market and nourished a systematic inspection to achieve the highest levels of rationality, control and efficiency which were characteristics of the periods of authoritarianism.

Keywords: middle school; dictatorship; space; time; organization of the school work.

\section{Introdução}

Este texto ancora-se no estudo e análise de um dos períodos da história da educação brasileira conhecido como História da escola pública propriamente dita $^{2}$, particularmente nas etapas de regulamentação nacional do ensino e do ideário pedagógico renovador (1931-1961), e no início da unificação normativa da educação nacional e da concepção produtivista de escola.

Para tanto, partimos da hipótese de que, no Brasil, o equilíbrio entre estas etapas estava associado à necessidade de alargamento da base social de apoio, de consolidação dos alicerces, de fundação da mentalidade das novas gerações nos princípios da educação cívica, possível apenas por meio de um programa educativo racionalmente concebido e sistematicamente implementado e sustentado, o ensino secundário. Dito de outra forma, a questão da moralidade em associação estreita com o civismo, a solidariedade social, a disciplina e a ordem, a justiça, o patriotismo.

Ao longo dos períodos históricos citados, mais especificamente de 1930 a 1985, o Brasil viveu uma história que pode ser grosseiramente classificada como de autoritarismos, iniciada como o governo provisório de Getúlio Vargas (19301937) que se transformou no regime ditatorial do Estado Novo (1937-1945), seguido de uma "ilha" de democratização carregada de tensões e possibilidades opostas de desenvolvimento (1945-1964), e atingiu seu auge com a ditadura civil-militar $^{3}$ (1964-1985).

Neste contexto, três marcos na legislação brasileira para o ensino secundário estão relacionados a esses três momentos e possibilitam a problematização das relações entre educação e ditaduras. São eles: "Reforma Francisco Campos" (Decreto-Lei 18.830 de 1931), elaborada e implantada no início do

2 Este período está identificado na periodização apresentada por Saviani (2004).

3 Adotamos aqui a opção de Gonçalves e Ranzi de denominar Ditadura Civil-Militar o período de 1964 a 1985 para indicar que "empresário, políticos, religiosos, estudantes e sindicatos, além da população de forma geral, participaram - apoiando diretamente e/ou omitindo-se dos governos desse período" (2012). 
Governo Provisório de Getúlio Vargas e complementada no Estado Novo, no conjunto das chamadas Leis Orgânicas (Reforma Capanema); a Lei 4.024 de 1961 (LDB), gestada e implantada no interregno "democrático" de 1945 a 1964, sancionada durante o governo João Goulart, e a Lei 5.692 de 1971, em pleno governo Médici, expressão consolidada das propostas educacionais da ditadura civil-militar iniciada em 1964.

Vale destacar que o conjunto das legislações não foi tomado como ponto de partida, mas de chegada, na medida em que cada uma das leis investigadas explicitou e induziu diretrizes curriculares que alteraram a organização do espaço, do tempo e do trabalho escolar nas escolas secundárias brasileiras.

Inquirir as relações e tensões entre educação e ditaduras, como é o propósito deste dossiê, implica problematizar o ordenamento jurídico relativo à educação, no período analisado, na direção enunciada por Faria Filho (2001), que consiste em considerar a legislação, educacional neste caso específico, como "expressão e construção das relações e lutas sociais" (FARIA FILHO, 2001, p. 260).

Nesse sentido, nos propomos a realizar aproximações na perspectiva de mapeamento e análise do mercado simbólico, entendido como aquele que, instituído por discursos, de ordem ideológica, designa determinados espaços habitados por múltiplas vozes que concorrem entre si, na produção e disseminação das três legislações básicas (Decreto-Lei 18.830, Lei 4.024 de 1961 e Lei 5.692 de 1971) e de alguns de seus complementos. Tais estudos serão desenvolvidos na perspectiva da história da educação comparada, elegendo como áreas de comparação: o espaço, o tempo e a organização do trabalho escolar que intentam explicitar o projeto educativo, delineados para configurar a educação como um lugar em que ocorrem determinações objetivas e pensadas, dentro da dinâmica de construção de sujeitos aptos a fazer parte das determinações sociais.

Para esta tarefa, estamos orientadas pelos fundamentos da História da Educação Comparada (NOVOA, 1998; COWEN, 1999) que nos colocam diante de procedimentos de pesquisa marcados, de um lado, pela identificação e análise de questões educativas definidas pela pertença geográfica, no sentido de uma interação com certos mercados simbólicos; de outro, pela filiação a uma historiografia que testemunhe uma produção social dos sentidos, que produzem e/ou fazem circular discursos.

Nesse sentido, historiadore ${ }^{4}$ convergem na interpretação de que, no longo período em que se situam esses dispositivos legais (1930-1971), forjou-se um pacto entre forças sociais nas quais alguns incluem "burguesia industrial, pequena-burguesia e operariado industrial" (WARDE, 1979, p. 64). Conside-

4 Ver, por exemplo: Germano (1993); Warde (1979). 
ramos, portanto, que, na análise dos dispositivos legais, fontes deste estudo comparado, é necessário levar em conta as expressões assumidas por esse pacto nos momentos históricos aqui focalizados e o seu rompimento em 1964.

\section{Tempos, espaços e organização do trabalho escolar no ensino secundário: os endereçamentos jurídico-formais}

O ensino secundário no Brasil teve início de forma sistemática em 1837, após a criação do Imperial Collegio de Pedro II, fundado, segundo Vechia e Cavazotti, "com a finalidade de educar a elite intelectual, econômica e religiosa brasileira e, concebido para ser o centro difusor das ideias educacionais, relativas ao ensino secundário" (2006, p. 83). Desde então, o ensino secundário passou por várias reformas, em âmbito nacional: Benjamin Constant (1890), Epitácio Pessoa (1901), Rivadávia Correa (1911), Carlos Maximiliano (1915) e João Luiz Alves (1925); Francisco Campos (1931), Gustavo Capanema (1942), Lei 4.024 (LDB) de 1961 e a Lei 5.692, de 1971, que uniu ensino primário e ensino secundário sob a denominação de Ensino de $1^{\circ}$ e $2^{\circ}$ graus.

Na década de 1940, Capanema confirmou, na Exposição de Motivos do Decreto-Lei 4.244, de 09 de abril de 1942, que o caráter específico desse nível de ensino se definia pela sua função de formar adolescentes com uma sólida cultura geral, marcada tanto pelas humanidades antigas quanto pelas humanidades modernas, e com elevada consciência patriótica e humanística (BRASIL, 1942).

Trata-se, portanto, de uma proposta de escolarização para os grupos dirigentes, "um luxo" a que o governo não destinava seus recursos. Ao restringir as possibilidades de acesso ao ensino superior aos poucos estabelecimentos de ensino secundário, em sua maioria, particulares, e conferir terminalidade real aos cursos técnico-profissionais, determinava-se a desigualdade de trajetórias segundo a origem social, com "raras exceções" (DALLABRIDA; CARMINATI, 2007, p. 19).

O estudo do conjunto da legislação que instituiu, organizou e regulou o ensino secundário no Brasil a partir de 1930 com a reforma Francisco Campos até a consolidação da primeira Lei de Diretrizes e Bases da Educação, n. 4.024, promulgada em 1961 e vigente até 1971, permitiu a aproximação com o protagonismo deste nível de ensino no delineamento de propostas de progresso moral e intelectual da juventude brasileira.

Contudo, este delineamento parece estar alinhavado em uma instituição de tempos e espaços com graus de especificidades que acabaram por delinear 
uma história curricular particular, isto é, com um sistema de práticas com seus agentes e com os meios e instrumentos por eles operados tendo em vista as finalidades perseguidas.

Marcado pela cronologia, o tempo escolar está diretamente vinculado aos ritmos da aprendizagem por parte dos agentes sociais, que constituem este espaço cronometrado, por meio dos tempos instituídos para o descanso, para as jornadas de trabalho, para as atividades, tudo isso organizado pelos calendários, fazendo da escola um lugar com regulamentações temporais necessárias para o seu funcionamento e controle.

Viñao Frago (1995) afirma a importância de se estudar o tempo escolar pelo seu caráter diverso, ao destacar que “[...] Não há um único tempo, senão uma variedade de tempos [...] o tempo escolar institucional oferece, por sua vez, diversas configurações ou níveis"5 (VIÑAO FRAGO, 1995, p. 72-73). A organização do tempo escolar se define tecnicamente pelos instrumentos utilizados para a sua efetivação, ou seja, os planejamentos, os horários, os calendários que ocupam grande parte das atenções da escola.

Já o espaço como construção social jamais é neutro, pelo contrário, carrega em sua configuração como território e lugar, signos, símbolos e vestígios da condição e das relações sociais daqueles que o habitam.

Os espaços educativos, como lugares que abrigam a liturgia acadêmica, estão dotados de significados e transmitem uma importante quantidade de estímulos, conteúdos e valores [...], ao mesmo tempo em que impõem suas leis como organizações disciplinares (VIÑAO FRAGO; ESCOLANO, 1998, p. 27).

É neste espaço instituído pela/para a escola que se desenvolve um processo de transformação de uma sociedade, que vê na escola o lugar para ensinar hábitos, para criar novos tempos e ocupá-los de modo a não desperdiçá-los, ou seja, uma economia do tempo por meio de uma utilização de espaços específicos para o desenvolvimento de atividades de ensino-aprendizagem.

E essas atividades passam a transitar entre a gestão dos sistemas escolares e a gestão da sala de aula e, nesse sentido, orientadas pelo trabalho de professores e alunos. A organização deste trabalho, entendido como escolar, é em si uma prática pedagógica que condiciona o encontro entre este conjunto de

5 No original: “[...] no hay un solo tiempo, sino una variedad de tiempos [...] el tiempo escolar institucional ofrece, a su vez, diversas configuraciones o niveles" (p. 72-73). 
estruturas, regras e práticas e a forma como as atividades estão discriminadas, como se dá a divisão dos tempos, a determinação dos ritmos e a distribuição das tarefas e competências.

De posse deste lugar para o qual projetamos as áreas de comparação, passamos a analisá-las a partir dos conteúdos propostos para a organização e o funcionamento do ensino secundário brasileiro, no período focalizado.

Nesse contexto, o governo federal assegura condições de existência e funcionamento ao ensino secundário, como aparato da formação da elite. Isso consolidou o sistema dual de ensino, que era reflexo da própria dualidade presente na organização da sociedade brasileira, realidade referendada pelas reformas ocorridas neste período, que tiveram o papel de concretizar a organização do ensino secundário.

Dualidade essa assumida, de um lado, pelo ensino de caráter propedêutico, voltado para as expressões locais da elite brasileira, delineadas, também, pela diversidade cultural e os regionalismos; de outro lado, pelo ensino profissional, que deveria preparar a juventude para acompanhar os rumos da revolução industrial.

O Decreto n. 19.890, de 18 de abril de 1931, conhecido como Reforma Francisco Campos, que dispõe sobre a organização do ensino secundário, em seu Art. $2^{\circ}$ apresenta a constituição deste nível de ensino em dois cursos seriados: fundamental e complementar, com distribuição diferenciada de matérias, constituindo uma história curricular assentada na diferenciação dos tempos de formação (BRASIL, 1931).

O curso fundamental, objeto do Art. $3^{\circ}$, estava organizado em 4 anos letivos com uma seriação fundada nas matérias Português, Francês, História da civilização, Geografia, Matemática, Ciências físicas e naturais, Desenho e Música (canto orfeônico). Seriação essa que somente seria alterada nos dois últimos anos letivos, quando haveria uma modificação na distribuição das matérias, a saber: além do Francês, Inglês, Latim e Alemão (facultativo); Ciências físicas e naturais dariam lugar a Física e Química; e acrescentava-se a História Natural.

No tocante ao curso complementar, teria dois anos de duração e as seguintes matérias: Alemão ou Inglês, Latim, Literatura, Geografia, Geofísica ou Cosmografia, História da Civilização, Matemática, Física, Química, História natural, Biologia geral, Higiene, Psicologia e Lógica, Sociologia, Noções de Economia e Estatística, História da Filosofia e Desenho (BRASIL, 1931, Art. $4^{\circ}$ ).

Assistimos por meio dessa organização à vigilância dos estudantes, à gestão centralizada, à racionalização e à organização dos estudos como uma modalidade concreta de ocupação do tempo. Para tal, estão cronometrados os programas das disciplinas, uma vez que deveriam considerar na sua organização a duração do ano letivo, de modo a ser ministrado todo o conteúdo de cada matéria. Acresce-se a isso que o ano letivo seria desenvolvido entre 15 de março e 30 de novembro. 
Dito de outro modo, a gestão do tempo vivido na escola faz do espaço escolar um lugar de vigilância mantida pela utilização dos horários, que acabam por manter as práticas e ações escolares fixas, predeterminando os trabalhos e gerenciando o tempo dos indivíduos.

A LDB de 1961, que apresenta o novo ensino secundário, denominado de ensino médio, propõe a separação em dois ciclos, a divisão entre o ginasial e o colegial, abrangendo "entre outros" (desse modo abrindo espaço para aparecimento de cursos não regulamentados até então), os cursos secundários, técnicos e de formação de professores para o ensino primário e pré-primário. Já nos artigos 44, 45 e 46, delineava-se uma variedade de organizações curriculares, desde que respeitadas as disciplinas obrigatórias a eles impostas, pois a instituição escolar poderia escolher quais disciplinas optativas estariam ajustadas às suas necessidades (BRASIL, 1961).

Contraditoriamente, essa, sem dúvida, era a primeira vez que se manifestava a articulação completa entre os ramos e níveis de ensino. No transcurso da década de 1960 a educação passou a ser considerada a principal variável para se obter um "[...] crescimento de renda, produzir a modernização ou construir uma sociedade mais justa" (CUNHA, 1985, p. 16).

Para cada um dos ciclos do ensino médio, a lógica da distribuição das disciplinas e práticas educativas, estava determinada pelos papéis desempenhados pelo Conselho Federal de Educação e Conselhos Estaduais, como especificado no ordenamento jurídico. Ao primeiro cabia determinar as disciplinas obrigatórias e aos segundos, a complementação dessa indicação com as disciplinas de caráter optativo que poderiam ser adotadas pelos estabelecimentos de ensino.

Nesse exercício, o currículo das duas primeiras séries do $1^{\circ}$ ciclo seria comum a todos os cursos de ensino médio no que se referia às matérias obrigatórias. Contudo, o ingresso na primeira série do $1^{\circ}$ ciclo dos cursos de ensino médio dependia de aprovação em exame de admissão e, para tanto, era preciso que ficasse demonstrada satisfatória educação primária, devendo o educando ter onze anos completos. $\mathrm{O}$ exame de admissão deveria ser realizado na segunda quinzena de fevereiro, composto de provas escritas e orais de Português, Aritmética e Conhecimentos Gerais, e se constituía em uma barreira para os egressos do curso primário que pretendiam continuar seus estudos.

Os dispositivos jurídico-formais (leis e decretos) estabelecidos pelos fatores organizacionais são responsáveis pelas determinações do tempo escolar. Estes dispositivos, com seus regulamentos podem afetar a macroestrutura do tempo, pois por meio dele impõem os números de dias necessários ao processo de escolarização vivido na escola, o início e o fim do ano letivo e o número de disciplinas que cada série deve ter para cumprir com as determinações de ensino-aprendizagem. 
Expressão dessa macroestrutura temporal já era encontrada no Decreto 19.890/1931, ao determinar que o horário escolar, organização de responsabilidade dos diretores das instituições de ensino secundário, estabelecesse a duração de cada aula, fixada em 50 minutos, e dos intervalos obrigatórios entre uma e outra, em 10 minutos, no mínimo. Para tal fixação, cada turma não poderia ter menos de 20 nem mais de 28 horas de aula por semana, excluídos desse tempo os exercícios de educação física e as aulas de música. Já na LDB a duração mínima do período escolar estabelecida era de cento e oitenta dias de trabalho escolar efetivo, não incluído o tempo reservado a provas e exames. Assim, ter-se-iam vinte e quatro horas semanais de aulas para o ensino de disciplinas e práticas educativas.

A sistematização do tempo, a centralidade dada à organização do tempo escolar termina sendo nuclear nas normas, regras e regulamentos específicos da carta magna das escolas. Em vários graus e detalhes, a coordenação e desdobramentos dos diferentes tempos, vivências, saberes e tarefas são assim assegurados e uniformizados (CORREIA, 1996, p. 109).

A padronização dos calendários escolares e a uniformidade dos tempos vividos são a própria materialidade deste nível de ensino, sistematizado em unidades, pedagogicamente organizadas e normatizadas por um tempo social. Nos dispositivos da Lei 5.692, é este mesmo tempo social que, influenciado por discussões em torno do civismo, para o qual os cidadãos, entre eles aqueles em formação, os sujeitos escolares, faziam parte de um "desenvolvimento com segurança" (ZOTTI, 2004).

Desenvolvimento esse pretendido por um desenho de educação cujo sentido de reforma estava a serviço da instauração de uma concepção de nação, fundada na ordem, de um Estado burocrático e autoritário (MARTINS, 2002). Imbuído deste espírito, o Grupo de Trabalho (GT) formado em 20 de maio de 1970 no Ministério da Educação tinha como incumbência realizar estudos e propor medidas à elaboração de uma nova Legislação Educacional. Tal tarefa culminou em 1971 com a promulgação da Lei $n^{0} 5.692$, que fixava normalizações para o ensino do $1^{\circ}$ e $2^{\circ}$ graus, além de outras providências destinadas à área educacional.

O primeiro artigo dessa Lei, em contraposição ao disposto na LDB 4.024, apresentava outras nomenclaturas para identificação dos graus de ensino, a saber: dividia o ensino em $1^{\circ}$ e $2^{\circ}$ graus, o $1^{\circ}$ grau subdividido em oito anos escolares 
e o $2^{\circ}$ grau, em 3 ou 4 anos escolares. Colocava por terra as denominações de Curso Primário, Ensino Primário, Curso Secundário, Ginasial, Ensino Secundário, Colegial e $1^{\circ}$ e $2^{\circ}$ ciclos. O ensino primário corresponderia ao de Primeiro grau e o ensino médio ao de Segundo grau, como explicitava o $\S 1^{\circ}$ do $\operatorname{art}^{\circ} 1^{\circ}$ da referida lei.

O ensino médio figurava nessa Lei vinculado à profissionalização, delegando a esse nível a formação de mão de obra especializada à indústria e ao comércio, servindo aos interesses dos grupos que compunham seu alicerce político e econômico, deixando claro qual seria o princípio educativo norteador de sua política econômica, sem que houvesse a preocupação de esconder tal objetivo. Tal vinculação se explicitava na chamada parte de formação especial de currículo que:

a) terá o objetivo de sondagem de aptidões e iniciação para o trabalho, no ensino de $1^{\circ}$ grau, e de habilitação profissional, no ensino de $2^{\circ}$ grau; b) será fixada, quando se destina a iniciação e habilitação profissional, em consonância com as necessidades do mercado de trabalho local ou regional, à vista de levantamentos periòdicamente renovados (BRASIL, 1971).

Acrescia-se a isso seu caráter de excepcionalidade, isto é, a parte especial do currículo poderia assumir, no ensino de $2^{\circ}$ grau, o caráter de aprofundamento em determinada ordem de estudos gerais, para atender a aptidão específica do estudante, por indicação de professores e orientadores.

No tocante à ordenação do currículo, o artigo $8^{\circ}$ indicava a realização por séries anuais de disciplinas ou áreas de estudo organizadas de forma a permitir, conforme o plano e as possibilidades do estabelecimento, a inclusão de opções que atendessem às diferenças individuais dos alunos e, no ensino de $2^{\circ}$ grau, ensejassem variedade de habilitações.

Em 1952, a Portaria n. 501, de 19 de maio ${ }^{6}$, foi determinante na configuração dos espaços-escola para/do ensino secundário. Espaços esses, pensados

6 No tocante aos espaços, esses já se encontravam como objeto desde o documento intitulado “Classificação dos Estabelecimentos de Ensino Secundário", elaborado por Anísio Teixeira, Paulo de Assis Ribeiro e Otávio Martins, orientados pelo Standards de Strayer e Engelhardt e publicado pelo Ministério da Educação e Saúde, em 1932. Encontrado também no artigo 51 do Decreto n 21.241, de 04 de abril de 1932, que consolida as disposições sobre a organização do ensino secundário, a saber: I - Dispor de edifício, instalações e material didático, de acordo com as normas estabelecidas pelo Departamento Nacional do Ensino e aprovadas pelo Ministro da Educação e Saúde Pública [...] (BRASIL, 1932). 
na idealização da eficiência, racionalidade e controle, para a qual a perspectiva da sistemática de inspeção tinha na construção do edifício e seu aparelhamento uma estratégia para a excelência.

No anexo II desta Portaria, que trata da verificação das condições materiais exigidas dos estabelecimentos de ensino secundário, realizada por um inspetor autorizado, encontramos na Divisão I, estabelecida em 250 pontos, quando da solicitação de Inspeção Prévia, os seguintes itens: Insalubridade; Ausência de ruídos; Ausência de perigos; Causas perturbadoras de atenção; Natureza e permeabilidade do terreno; Regularidade do terreno; Área coberta para recreio e abrigo; Área livre.

Cada um dos itens destacados no anexo II apresenta-se acompanhado de especificações particulares da interpretação dos mesmos, e essas servem para estabelecer uma relação entre os aspectos interno e externo, eles devem ser pensados e projetados para serem uma instituição com consciência social e de caráter permanente, estimulando o trabalho e a convivência de todos que compõem este cenário educativo. Os edifícios escolares tornam-se exemplos dos aspectos estéticos da aprendizagem e da vida.

Nesta perspectiva, a Divisão II, que vale 300 pontos, se organiza em torno da Disposição Interna (distribuição das salas no corpo do edifício, indicações de forma E, U, H, T e L); Situação (três faces isoladas dos prédios vizinhos); Número de pavimentos (satisfatórios os de 2 ou 3); Material e conservação; Entradas (geral e secundárias).

Tais requisitos parecem ser produzidos de forma a interpretar os desejos simbólicos, as ideias funcionais que os indivíduos fazem dela, isto é, um lugar com códigos que representam a sua real função, a de educar, de disciplinar, de instruir e de preparar os indivíduos para viverem em uma sociedade que está organizada de acordo com tempos e espaços a serem utilizados para determinações específicas.

Dotando esses espaços "de vida escolar", a Divisão IV (500 pontos) tem como principal item avaliativo a sala de aula, concebida nos quesitos número, área, forma, isolamento, quadros negros, pintura, área de iluminação, disposição das janelas, acústica, carteiras e móveis diversos e reflete aquilo que é entendido como concepção educativa. O espaço da sala de aula deve contemplar determinações de uso, de ação, sendo o reflexo de espaço culturalmente construído para este determinado fim - o de ensinar.

Considerando esse fim, o de ensinar, a Divisão V (500 pontos) amplia e localiza essa prática nos espaços das Salas Especiais e Material Didático. Entre os quesitos avaliativos dessa divisão merecem destaque a Biblioteca, a Sala de Línguas Vivas, o Laboratório e a qualidade dos materiais que deveriam ser alocados em seus interiores. 
Como a arquitetura escolar é uma espécie de programa de ensino, onde estão descritas as regras a serem seguidas de acordo com o desenho da escola, com as suas determinações prescritas, delimitando como cada espaço deve ser utilizado, todos inscritos dentro de uma dinâmica interna da escola com as suas funções, a Biblioteca, a Sala de Línguas Vivas, o Laboratório, nada mais induzem do que a imposição de novos ritmos aos acontecimentos educativos, descrevendo cada ação e seu respectivo espaço de execução.

Cabe ressaltar que a Portaria n. 501, de 19 de maio de 1952, revogada em novembro de 1957, ao requisitar maior atenção aos espaços do ensino secundário, expresso em espaços educativos, parece ter aliado objetivos políticos, sociais e culturais de uma sociedade que entendia este nível de ensino para além do interesse na formação dos futuros cidadãos, métodos e critérios.

Guardadas as análises e seus limites, inferimos que o cumprimento das tarefas requeridas nas reformas do ensino secundário deu conta de registrar o processo de mudança de regime, com vista a reorganizar e regular uma política educacional que se desenvolveu em torno dos seguintes eixos:

1) Controle político e ideológico da educação escolar, em todos os níveis; 2) Estabelecimento de uma relação direta e imediata, segundo a teoria do capital humano, entre educação e produção capitalista e que aparece de forma mais evidente na reforma do ensino de $2^{\circ}$ grau através da pretensa profissionalização; 3) Incentivo a pesquisa vinculada à acumulação de capital; 4) Descomprometimento com o financiamento da educação pública e gratuita, negando na prática o discurso de valorização da educação escolar e concorrendo decisivamente para a corrupção e privatização do ensino, transformando em negócio rendoso e subsidiado pelo Estado (GERMANO, 1993, p. 105).

No tocante à comparação dos tempos, dos espaços e da organização do trabalho nos três momentos históricos analisados, foram encontradas mais semelhanças entre as prescrições, ou no que diz respeito ao mercado simbólico, talvez resultado da interpretação dos agentes proponentes (legisladores, educadores entre outros) orientados por um habitus internalizado, qual seja história incorporada, feita segunda natureza. História essa marcada pelas expectativas políticas e sociais da capacidade brasileira de resolver seus problemas educativos, o que acabou por colocar o ensino secundário como objeto de disputa entre as classes.

Disputa que se configurou, de um lado, pelo grupo composto por certas camadas da burguesia cujo processo de mobilidade social vertical descendente 
provocou sua proletarização econômica e social e, de outro, pelo grupo originado de determinadas frações das camadas de trabalhadores urbanos, que se beneficiariam da massificação do ensino superior.

As reformas educacionais analisadas nesse recorte temporal pautavam-se em discursos e ações defendidas no intuito de aliar as políticas educacionais ao desenvolvimento, colocando o ensino secundário na condição de controle ideológico, dessa forma atendendo aos interesses do capital. O que se confirma nos acordos entre Ministério da Educação e Cultura e Agency for International Development dos Estados Unidos (USAID) ${ }^{7}$.

Por fim, os tempos, os espaços e a organização do trabalho escolar foram analisados na perspectiva de serem compreendidos como mais uma ferramenta para o entendimento das relações de dominação presentes na estrutura do ensino secundário brasileiro, ou melhor, uma maneira de apreensão da dimensão simbólica da luta entre os diferentes grupos sociais que constitui esse nível de ensino.

Cabe destacar que, entre o Decreto n. 19.890 de 1931 e 1945, a política educacional assumiu um caráter centralizador, em consonância com o centralismo do Estado autoritário, forjado principalmente no governo de Getúlio Vargas, que se expressava na ausência do Parlamento, com o chefe de Estado legislando, discricionariamente, em matéria de ensino, como em todas as outras matérias; veja-se, por exemplo, que praticamente toda a legislação referente ao ensino secundário no período de 1931 a 1946 assumiu a forma jurídica de decretos, decretos-lei ou Portarias ${ }^{8}$.

Esta constatação confirma que, em tempos de autoritarismo, as disputas entre as diversas forças sociais em luta por hegemonia são escamoteadas e perdem a visibilidade. Explicitando-se por meio de dispositivos legais emanados do poder executivo, divulga-se a ideia de que são resultado de um consenso, e, até mesmo, de unanimidade, uma vez que não há registro dos debates parlamentares. Mesmo a Lei 5.692 de 1971, embora aprovada em curta tramitação ${ }^{9}$ por um congresso submetido ao AI-5, não registrou debates acalorados.

7 Os acordos MEC-USAID, que embalaram as reformas educacionais da ditadura, foram assinados e executados entre 1964 e 1968, alguns com vigência até 1971.

8 Inclusive os dois dispositivos legais mais importantes do período, a Reforma Francisco Campos, promulgada por Decreto (n. 19.890/1931), e a Reforma Capanema que, embora tenha recebido no texto legal o título de Lei Orgânica do Ensino Secundário, também foi promulgada pelo Decreto 4244 de 1942.

9 De 28 de junho de 1971, quando o presidente do Senado convocou sessão conjunta para apreciar a matéria, até a promulgação da Lei em 11 de agosto de 1971. Período curtíssimo se comparado com os longos 11 anos em que tramitou a LDB de 1961. 


\section{Notas finais}

O estudo dessas áreas de comparação, no conjunto dos documentos selecionados, bem como nos distintos recortes temporais (1931, 1961 e 1971), indicou evidências de uma intervenção menos estruturante na interpretação de suas diretrizes. Intervenção essa desvelada pela inexistência de alterações de fundo no ensino secundário, desde a reforma empreendida pelo Decreto 19.890/1931, confirmada pela LDB 4.024/1961 e alterada pela Lei 5.692/1971.

Parece ser a partir da organização do ensino primário que se inovou a oferta curricular secundária, com base no princípio da educação universal e gratuita garantido por aquele nível de ensino, que sempre contou com maior concentração de recursos humanos e materiais e, do ponto de vista financeiro, com maior investimento por parte do Estado.

Além disto, tal desvelamento permitiu-nos observar que também essas reformas carregaram vestígios históricos da instituição de uma educação secundária, objeto de um processo civilizatório. Processo esse identificado nas dificuldades de trânsito social e educativo entre diferentes concepções do ensino secundário, uma fundada nas nuances do capital econômico e outra, objetivada pelas localizações do capital cultural. A primeira destinada a formar o sujeito que ingressaria na Universidade e a segunda, um trabalhador para uma área em ascensão, qual seja, a indústria.

O capital cultural que seria distribuído pelo primeiro formato, o ensino secundário "de/para elite", depende diretamente da divisão do trabalho e do poder de uma sociedade. Já no caso do ensino secundário "para/do trabalhador", era uma criação a priori, mantida por um sistema desigual, que foi produzido e reproduzido por meio da transmissão cultural, que mantinha uma relação dialética entre o acesso ao poder e a oportunidade de legitimação de alguns conhecimentos vistos como dominantes.

Segundo Apple (2006, p. 179), "[...] muito da linguagem que utilizamos, embora aparentemente neutra, não é neutra no impacto que causa, nem é imparcial no que diz respeito às instituições de ensino existentes".

Neste contexto, o tempo, o espaço e a organização do trabalho escolar, no conjunto das medidas adotadas para a idealização/renovação do ensino secundário, mereceram especial atenção, uma vez que asseguravam a instituição e comunicação de diferentes signos e significados, no que estamos chamando de mercado simbólico, ao mesmo tempo em que alimentavam uma sistemática de inspeção, por meio da qual poderiam ser alcançados níveis mais altos de racionalidade, controle e eficácia característicos dos períodos de autoritarismo. 
A força disciplinadora do tempo, espaço e trabalho escolar inaugurada com a Reforma Francisco Campos, mantida na Lei de Diretrizes e Bases da Educação n. 4.024 e diluída na Lei 5.692, foi aqui sentida na estrutura prescrita para a formação no ensino secundário, dotada de um conjunto de programas, de métodos, de critérios de inspeção e do sistema de avaliação, os quais parecem alimentar a tese da "relação com o poder constituído".

Tese essa expressa, de um lado, na ampliação do clientelismo e do poder político local, por meio da gestão das municipalidades dos recursos públicos a serem destinados ao ensino básico e, de outro, na ampliação da classe média provocando uma "nova clientela" para a escola privada, que passava a ser símbolo de status e alternativa ao ensino público estatal que se deteriorava. Deterioração essa orquestrada contraditoriamente, em meio às tentativas de produção dos mecanismos de desenvolvimento acelerado de acumulação de capital, ao mesmo tempo que a garantia do acesso da população aos direitos de bem-estar social.

Isto ativado diretamente por um conjunto progressivo de programas curriculares que, ao longo do recorte temporal aqui definido, foi se alterando, em nome da consolidação da estrutura do capital humano para a aceleração do desenvolvimento econômico, instituída por meio de disciplinas cuja formação primava por uma espécie de práticas morais e civilizatórias, em ligação estreita com a formação dos agentes.

Contudo, há que se ressaltar uma tensão entre essa espécie de práticas, cujo objeto, ainda que delineado pelo controle e disciplinamento, nos permitiu observá-las como produtos de uma ideologia incorporada, qual seja, a atuação do ensino secundário no processo de reprodução das relações de produção, pela defesa da eficiência técnica. E é exatamente essa observação que minimiza a violência simbólica, caracterizada por um arbitrário cultural, pela imposição de padrões e práticas culturais, resultantes do discurso de encontro de medidas favoráveis ao aumento de oportunidades escolares.

\section{REFERÊNCIAS}

APPLE, M. W. Ideologia e currículo. Porto Alegre: ArtMed, 2006.

BRASIL. Decreto n ${ }^{\circ} 19.890$, de 18 de abril de 1931. Dispõe sobre a organização do ensino secundário. Diário Official, Rio de Janeiro, 1 maio 1931.

Decreto $\mathrm{n}^{\circ} 21.241$, de 4 de abril de 1932. Consolida as disposições sobre a organização do ensino secundário e dá outras providências. Diário Official, Rio de Janeiro, 9 abr. 1932. 
. Decreto-Lei no 4.244, de 9 de abril de 1942. Lei Orgânica do Ensino Secundário. Diário Oficial da União, Rio de Janeiro, 10 abr. 1942.

. Lei n ${ }^{\circ}$ 4.024, 20 de dezembro de 1961. Fixa as Diretrizes e Bases da Educação Nacional. Diário Oficial da União, Brasília, DF, 27 dez. 1961.

. Lei $\mathrm{n}^{\circ}$ 5.692, de 11 de agosto de 1971. Fixa as Diretrizes e as Bases para o ensino de $1^{\circ}$ e $2^{\circ}$ graus, e dá outras providências. Diário Oficial da União, Brasília, DF, 18 ago. 1971.

CORREIA, T. S. L. Tempo de escola ... e outros tempos (quem viveu assim, sabe. E quem não viveu... que pena!). Manaus: Universidade do Amazonas, 1996.

COWEN, Robert. Late modernity and the rules of chaos: an initial note on transitologies and rims. In: ALEXANDER, R.; BROADFOOT, P.; PHILLIPS, D. (Ed.). Learning from comparing: new directions in comparative educational research. Oxford: Symposium Books, 1999. p. 73-88.

CUNHA, L. A. Educação e Desenvolvimento Social no Brasil. Rio de Janeiro: Francisco Alves, 1985.

DALLABRIDA, Norberto; CARMINATI, C. J. O tempo dos ginásios: ensino secundário em Santa Catarina. São Paulo: Mercado das Letras, 2007.

FARIA FILHO, L. M. Fazer história da educação com E. P. Thompson: trajetórias de um aprendizado. In: FARIA FILHO, L. M. (Org.). Pensadores sociais e história da educação. Belo Horizonte: Autêntica, 2001. p. 247-264.

GERMANO, J. W. Estado e educação no Brasil (1964-1985). São Paulo: Cortez, 1993.

GONÇALVES, N. G.; RANZI, S. M. E. (Orgs.). Educação na ditadura civil-militar: políticas, ideários e práticas (Paraná, 1964-1985). Curitiba: UFPR, 2012.

LIRA, A. T. N. A legislação de Educação no Brasil durante a ditadura Militar (19641985): um espaço de disputas. Tese (Doutorado em História Social) - Universidade Federal Fluminense, Niterói, 2010.

MARTINS, M. C. A história prescrita e disciplinada nos currículos escolares: quem legitima esses saberes?. Bragança Paulista: Universidade São Francisco, 2002.

NOVOA, Antonio. Histoire \& comparaison. Lisboa: Educa, 1998.

SAVIANI, Dermeval. O Legado Educacional do Século XX no Brasil. São Paulo: Autores Associados, 2004.

VECHIA, Ariclê; CAVAZOTTI, M. A. (Org.). A escola secundária: modelos e planos (Brasil, séculos XIX e XX). São Paulo: Annablume, 2003.

VIÑAO FRAGO, Antonio; ESCOLANO, Augusto. Currículo, espaço e subjetividade: a arquitetura como programa. Tradução Alfredo Veiga-Neto. Rio de Janeiro: DP\&A Editora, 1998. 
VIÑAO FRAGO, Antonio. Historia de la educación y historia cultural: posibilidades, problemas, cuestiones. Revista Brasileira de Educação, Campinas, n. 0, p. 63-82, set./ dez. 1995.

WARDE, M. J. Educação e estrutura social: a profissionalização em questão 2. ed. rev. São Paulo: Cortez \& Moraes, 1979.

ZOTTI, S. A. Sociedade, educação e currículo no Brasil: dos jesuítas aos anos de 1980. Campinas: Autores Associados; Brasília, DF: Plano, 2004.

Texto recebido em 22 de janeiro de 2014 Texto aprovado em 09 de fevereiro de 2014. 